05

\title{
Модифицирование магнитных свойств сплава CoPt путем ионного облучения
}

\author{
(c) И.Л. Калентьева ${ }^{1}$, О.В. Вихрова ${ }^{1, \uparrow}$ Ю.А. Данилов ${ }^{1}$, М.В. Дорохин ${ }^{1}$, Ю.А. Дудин ${ }^{1}$, А.В. Здоровейщев ${ }^{1}$, \\ А.В. Кудрин ${ }^{1}$, М.П. Темирязева ${ }^{2}$, А.Г. Темирязев ${ }^{2}$, С.А. Никитов ${ }^{3,4,5}$, А.В. Садовников ${ }^{3,4}$ \\ ${ }^{1}$ Научно-исследовательский ффизико-технический институт, \\ Национального исследовательского Нижегородского государственного университета им. Н.И. Лобачевского, \\ Нижний Новгород, Россия \\ ${ }^{2}$ Фрязинский филиал Института радиотехники и электроники им. В.А. Котельникова РАН, \\ Фрязино, Россия \\ ${ }^{3}$ Лаборатория „Метаматериалы“ Саратовского государственного университета, \\ Саратов, Россия \\ ${ }^{4}$ Институт радиотехники и электроники им. В.А. Котельникова РАН, \\ Москва, Россия \\ ${ }^{5}$ Московский фризико-технический институт, \\ Долгопрудный, Россия \\ E-mail: vikhrova@nifti.unn.ru
}

Поступила в Редакцию 15 апреля 2019 г.

В окончательной редакции 22 апреля 2019 г.

Принята к публикации 24 апреля 2019 г.

Исследовано влияние ионного облучения на магнитные свойства пленок ферромагнитного сплава $\mathrm{CoPt}$, изготовленного методом электронно-лучевого испарения. Установлено, что с увеличением флюенса ионов $\mathrm{He}^{+}$от $1 \cdot 10^{13}$ до $1 \cdot 10^{16} \mathrm{~cm}^{-2}$ наблюдается уменьшение коэрцитивного поля и увеличение латеральной составляющей оси легкого намагничивания. Методами магнитно-силовой микроскопии и мандельштам-бриллюэновской спектроскопии показано, что при определенных флюенсах ионного облучения $\left(3 \cdot 10^{14} \mathrm{~cm}^{-2}\right)$ в слое CoPt наблюдается активация образования изолированных круглых доменов, представляющих собой магнитные скирмионы.

Ключевые слова: электронно-лучевое испарение, ферромагнитный сплав, ионное облучение, изолированные круглые домены.

DOI: 10.21883/FTT.2019.09.48112.20N

\section{1. Введение}

Возможность модифицирования ферромагнетизма пленок $\mathrm{CoPt}$ при управляемом радиационном воздействии исследована в ряде работ. Так, в [1] показано, что при облучении ионами гелия с энергией $30 \mathrm{keV}$ через литографически изготовленную маску магнитные свойства структур кобальт-платина (двухслойных и многослойных) можно изменять без воздействия на их шероховатость и оптические свойства. Установлено, что ортогональная анизотропия намагниченности понижалась, а коэрцитивная сила уменьшалась с увеличением флюенса ионов от $2 \cdot 10^{14}$ до $2 \cdot 10^{16} \mathrm{~cm}^{-2}$. $\mathrm{B}$ более поздней работе [2] с помощью магнитооптического эффекта Керра была определена магнитная фазовая диаграмма ультратонких пленочных структур $\mathrm{Pt} / \mathrm{Co}(t) / \mathrm{Pt}$, равномерно облученных ионами Не, в плоскостях $(T, F)$ и $(t, F)$, где $F-$ флюенс ионов, $T-$ температура и $t$ - толщина пленки кобальта. Были идентифицированы три ферромагнитных состояния: с осью легкого намагничивания, расположенной перпендикулярно плоскости, в плоскости и под углом к плоскости слоя. Для фиксированной толщины Со ось легкого намагничивания, перпендикулярная плоскости слоя, сохранялась при низком флюенсе облучения, в то время как при более высоком флюенсе возникало расположение оси легкого намагничивания в плоскости слоя или под наклоном. Авторы [2] показали, что использование ионного облучения позволяет контролировать постепенную эволюцию магнитной системы.

В работах $[3,4]$ приводятся результаты исследований магнитно-силовой микроскопией доменной системы в многослойных $[\mathrm{Co}(0.5 \mathrm{~nm}) / \mathrm{Pt}(1 \mathrm{~nm})]_{5}$ тонкопленочных структурах, модифицированных формированием дополнительного покровного слоя Со толщиной $1.3 \mathrm{~nm} \mathrm{в}$ процессе магнетронного распыления и последующим ионным облучением. Показано, что покровный слой Со существенно изменяет доменную структуру и уменьшает порог размагничивания из-за образования неколлинеарной намагниченности в $\mathrm{Co} / \mathrm{Pt}$. Многослойные структуры $\mathrm{Co} / \mathrm{Pt}$ с перпендикулярной магнитной анизотропией облучались сфокусированным пучком ионов $\mathrm{He}^{+}$(энергия ионов $30 \mathrm{keV}$, флюенс варьировался от $1 \cdot 10^{15}$ до $4 \cdot 10^{15} \mathrm{~cm}^{-2}$ ), что позволяет локально уменьшить степень ортогональной анизотропии [4]. Облученные пятна диаметром $100 \mathrm{~nm}$ располагались в квадратной решетке 
с периодом $200 \mathrm{~nm}$. В результате облучения в таком режиме наблюдалось формирование неоднородной периодической магнитной структуры без изменений в топографии пленки. Пространственная симметрия сигнала магнитно-силовой микроскопии и форма полученных кривых намагничивания указывали на образование магнитных „пузырьков“ или магнитных вихрей (скирмионподобные состояния) внутри облученного пятна в зависимости от дозы облучения. Экспериментальные данные находились в хорошем согласии с микромагнитным моделированием системы [4].

Настоящая работа посвящена исследованию возможности модифицирования магнитных свойств металлических пленок $\mathrm{CoPt}$, изготовленных методом электроннолучевого испарения в высоком вакууме, с помощью ионного облучения. Изготовленные слои $\mathrm{CoPt}$ имеют ось легкого намагничивания, перпендикулярную плоскости слоя, сохраняют остаточную намагниченность при комнатной температуре и могут быть использованы для оптоэлектронных приборов спинтроники [5,6]. Ранее было показано, что в таких пленках могут существовать изолированные домены, по форме и размерам подобные магнитным скирмионам. Отметим, что наблюдавшиеся скирмионы были устойчивы в отсутствие внешнего магнитного поля, что, несомненно, представляет практический интерес [7]. На сегодняшний день круг ферромагнитных материалов, в которых наблюдают скирмионы, значительным образом расширился [8]. Основной интерес к изучению скирмионов обусловлен возможностью их перемещения внутри пленки под действием электрического тока, и, очевидно, подобные эффекты могут найти применение при создании устройств хранения и обработки информации.

\section{2. Методика эксперимента}

Исследуемые структуры представляли собой пленки сплава $\mathrm{Co}_{45} \mathrm{Pt}_{55}$, для получения которого методом электронно-лучевого испарения при $200^{\circ} \mathrm{C}$ на подложки $i$-GaAs (001) поверх предварительно осажденного тонкого $(\sim 1 \mathrm{~nm})$ слоя $\mathrm{Al}_{2} \mathrm{O}_{3}$ поочередно наносились слои $\mathrm{Pt}(0.5 \mathrm{~nm})$ и Со $(0.3 \mathrm{~nm})$. Тонкий слой оксида алюминия необходим для предотвращения диффузии атомов Со в подложку GaAs [5,6]. Общая толщина пленки $\mathrm{CoPt}$ составляла $\sim 8 \mathrm{~nm}$. Как было показано ранее с использованием рентгеновской фотоэлектронной спектроскопии с послойным профилированием по глубине за счет ионного распыления материала образца, указанное выше соотношение толщин слоев $\mathrm{Pt}$ и Со соответствует сплаву $\mathrm{Co}_{0.45} \mathrm{Pt}_{0.55}$ [9]. Исследования структурных свойств пленок $\mathrm{CoPt}$ посредством просвечивающей электронной микроскопии обнаружили, что они являются поликристаллическими и не демонстрируют „слоистости“, обусловленной поочередным осаждением слоев $\mathrm{Pt}(0.5 \mathrm{~nm})$ и $\mathrm{Co}(0.3 \mathrm{~nm})[9]$.
Структуры разделялись на образцы размером $6 \times 6 \mathrm{~mm}$, которые равномерно облучались на ускорителе ИЛУ-3 ионами $\mathrm{He}^{+}$с энергией $20 \mathrm{keV}$, флюенс варьировался от $1 \cdot 10^{13}$ до $1 \cdot 10^{16} \mathrm{~cm}^{-2}$. Выбор энергии ионов гелия и диапазона изменения флюенса ионов был сделан с учетом расчетов распределения возникающих вследствие ионного облучения дефектов по глубине структур, проведенных с использованием программы SRIM [10], и калькулятора, позволяющего делать оценки коэффициента распыления материала при ионном облучении [11].

Исходные и облученные образцы изучались методами атомно- и магнитно-силовой микроскопии (АСМ и МСM) при помощи атомно-силового микроскопа SmartSPM (AIST-NT) с использованием зондов двух типов: зондов с низким магнитным моментом (покрытых CoPt) и зондов PPP-LM-MFMR (Nanosensors). Исследовались магнитооптические свойства: эффект Фарадея и поперечный (экваториальный) эффект Керра (TKE) на длинах волн лазерного излучения 980 и $800 \mathrm{~nm}$ соответственно. Для регистрации угла Фарадея внешнее магнитное поле прикладывается перпендикулярно поверхности пленок. При исследовании ТKЕ магнитное поле лежит в плоскости пленки. В обоих случаях регистрируемое магнитополевое изменение интенсивности прошедшего (отраженного) сигнала пропорционально изменению намагниченности. Намагниченность $M$ образцов измерялась посредством магнитометра с переменным градиентом поля.

Кроме того, образцы исследовались с использованием мандельштам-бриллюэновской спектроскопии (МСБ) магнитных материалов. Метод МБС позволяет проводить исследования пространственно-неоднородной прецессии магнитных моментов (спиновые возбуждения с различными волновыми числами) в ферро- и ферримагнитных материалах [12] на частотах в диапазоне от 1 до $500 \mathrm{GHz}$. Анализ сдвигов стоксовой и антистоксовой частот рассеяния Мандельштама-Бриллюэна в данном случае позволяет оценить величину энергии взаимодействия Дзялошинского-Мория (ВДМ). Данный параметр является одним из ключевых при интерпретации скирмионных состояний в магнитной среде $[4,8,13]$.

Все исследования проведены при комнатной температуре.

\section{3. Экспериментальные результаты и их обсуждение}

Магнитополевые зависимости угла Фарадея $\left(Q_{\mathrm{F}}(H)\right)$ (рис. 1) и намагниченности, измеренной при приложении внешнего магнитного поля перпендикулярно плоскости образца, (вставка на рис. 3) исходного образца CoPt имеют подобный вид и содержат петлю гистерезиса с коэрцитивным полем $\sim 500$ Ое. Величина остаточной намагниченности $M_{R}$ совпадает с намагниченностью насыщения $M_{S}$. Следовательно, можно говорить о наличии 
ярко выраженной ортогональной анизотропии магнитных свойств исходных пленок CoРt. Как видно из зависимостей $Q_{\mathrm{F}}(H)$, для облученных образцов наблюдается сужение петли до $\sim 100-150$ Ое и уменьшение угла Фарадея в нулевом магнитном поле, что свидетельствует о снижении остаточной намагниченности с увеличением флюенса $\mathrm{He}^{+}$от $1 \cdot 10^{13}$ до $1 \cdot 10^{15} \mathrm{~cm}^{-2}$. При флюенсе ионов $\geq 1 \cdot 10^{15} \mathrm{~cm}^{-2}$ значительным образом увеличивается латеральная составляющая оси легкого намагничивания сплава CoPt. Это подтверждается измерениями поперечного эффекта Керра, представленными на рис. 2 и показывающими возрастание величины остаточной намагниченности на зависимостях $\operatorname{TKE}(H)$. Данные рис. 3 демонстрируют наиболее полную картину изменения относительных величин остаточной намагниченности $\left(M_{R} / M_{S}\right)$ в двух геометриях приложения

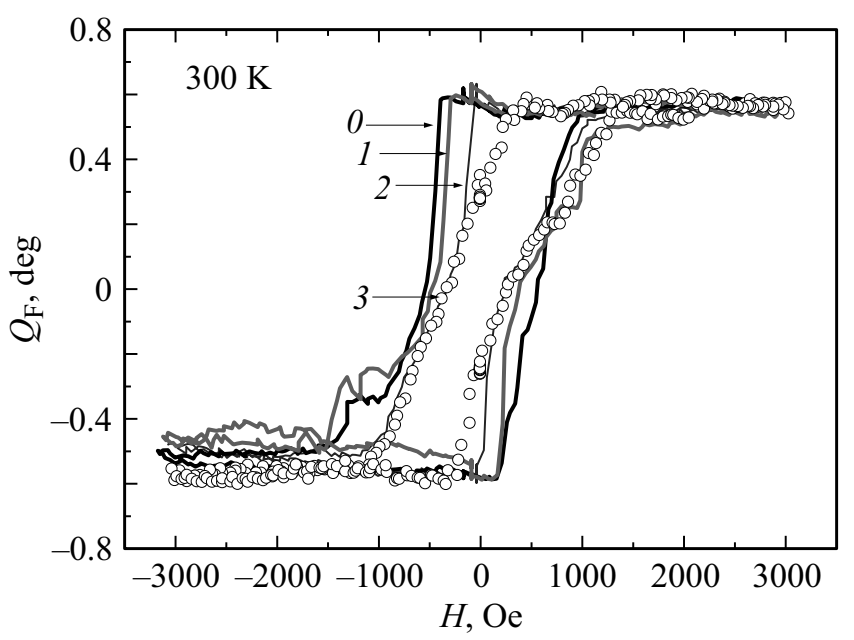

Рис. 1. Магнитополевые зависимости угла Фарадея при различных флюенсах ионов, $\mathrm{cm}^{-2}: 0-$ исходная структура, $1-5 \cdot 10^{13}, 2-3 \cdot 10^{14}, 3-5 \cdot 10^{14}$. Магнитное поле приложено перпендикулярно поверхности пленки CoPt.

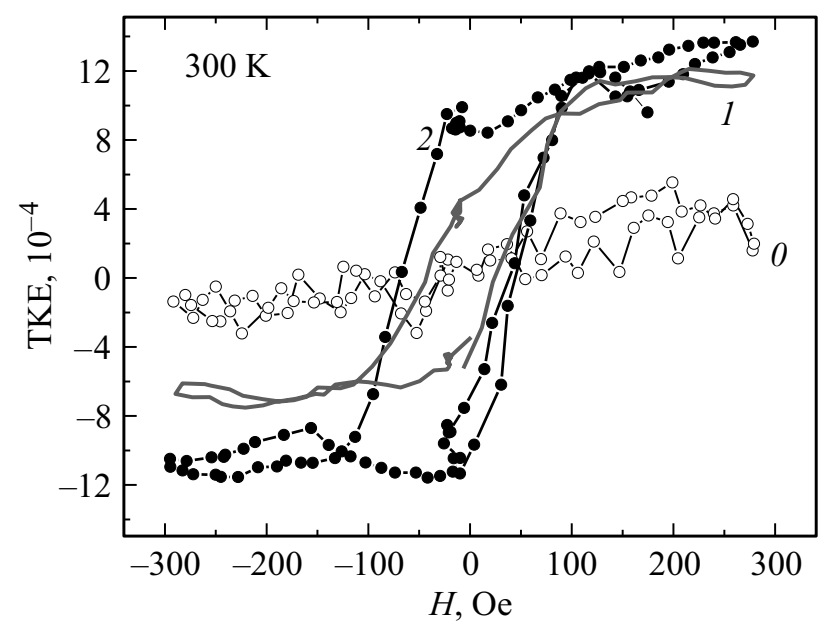

Рис. 2. Магнитополевые зависимости ТКЕ при различных флюенсах ионов, $\mathrm{cm}^{-2}: 0-$ исходная структура, $1-1 \cdot 10^{15}$, $2-5 \cdot 10^{15}$. Магнитное поле лежит в плоскости пленки CoPt.

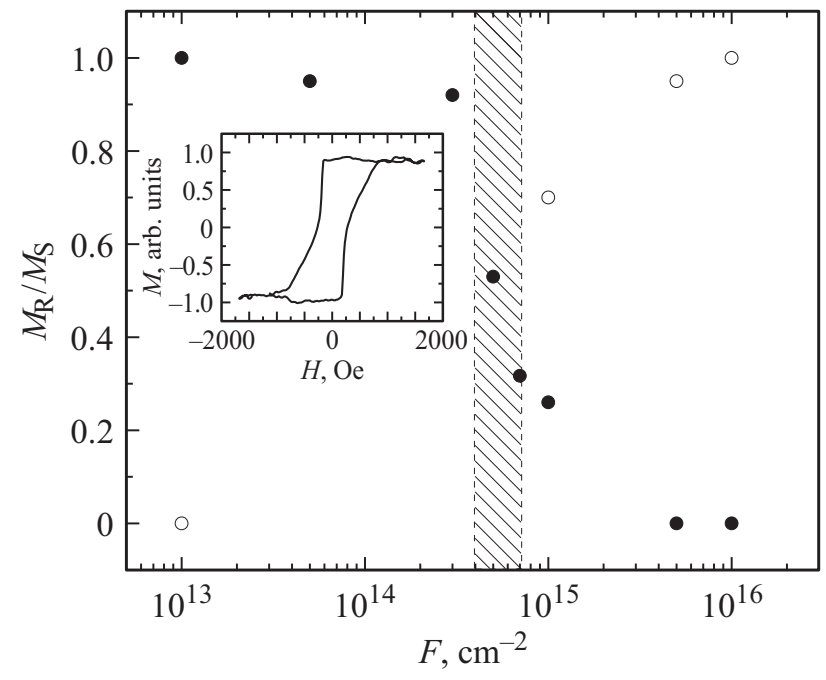

Рис. 3. Относительные значения остаточной намагниченности $\left(M_{R} / M_{S}\right.$, где $M_{S}$ - намагниченность насыщения) при различных флюенсах ионов гелия $(20 \mathrm{keV})$ : темные кружки соответствуют остаточной намагниченности для внешнего магнитного поля, перпендикулярного слою $\mathrm{CoPt}$; светлые кружки остаточной намагниченности для внешнего магнитного поля, приложенного параллельно слою CoPt. На вставке показана магнитополевая зависимость намагниченности исходного образца пленки CoPt. Магнитное поле приложено перпендикулярно поверхности.

внешнего магнитного поля. Темные кружки показывают зависимость остаточной намагниченности от флюенса ионов гелия для магнитного поля, перпендикулярного поверхности пленки $\mathrm{CoPt}$, а светлые кружки - зависимость остаточной намагниченности от флюенса $\mathrm{He}^{+}$ для магнитного поля, приложенного параллельно слою CoPt. Видно, что достижение критического значения флюенса (заштрихованная область на рис. 3), приводит к значительному ослаблению ортогональной магнитной анизотропии.

АСМ-исследования выявили, что шероховатость исходных и облученных пленок CoPt остается низкой, величина среднеквадратичной высоты неровностей не превышает $\sim 0.5 \mathrm{~nm}$. Другими словами, используемое в экспериментах ионное облучение не привело к возникновению заметных изменений в морфологии поверхности образцов.

МСМ-измерения пленок осуществляли двумя способами. Первый способ заключался в „стандартном“ сканировании пленок в два прохода зондом, который имеет низкий магнитный момент и не перемагничивает образец. Полученные МСМ изображения представлены на рис. 4, a, c, e,g. На изображениях видна лабиринтная доменная структура, причем каких-либо закономерностей ее изменения в результате облучения ионами гелия с различным флюенсом не наблюдается. Второй способ сканирования заключался в предварительном создании доменной структуры посредством измерения пленок 

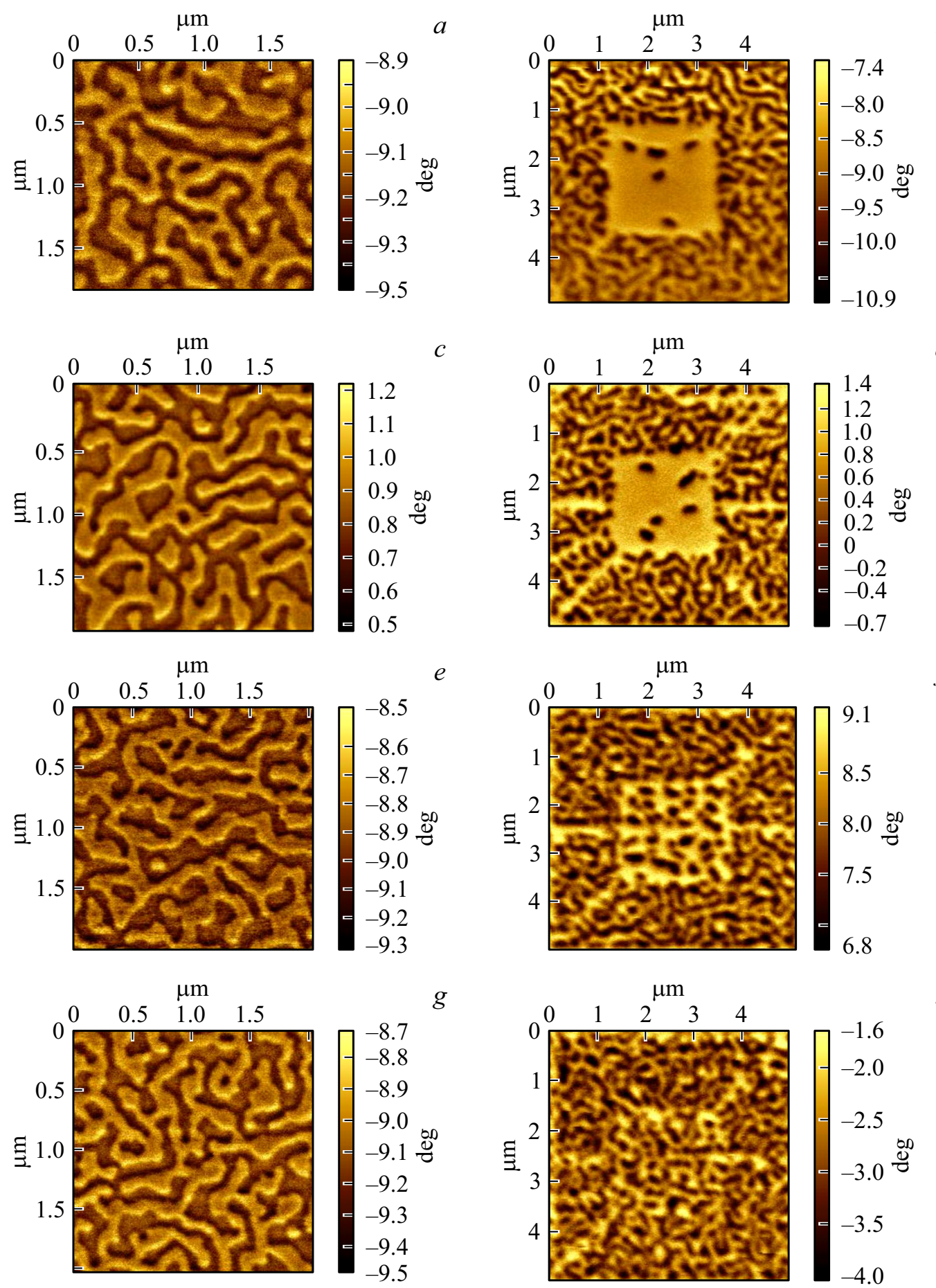

Рис. 4. Изображения пленок CoPt: исходной $(a, b)$ и облученной ионами $\mathrm{He}^{+}$(энергия ионов $\left.20 \mathrm{eV}\right) \mathrm{c}$ различными флюенсами $\left(c, d-5 \cdot 10^{13} ; e, f-3 \cdot 10^{14} ; g, h-5 \cdot 10^{14}\right)$, полученные при сканировании зондом с покрытием CoPt $(a, c, e, g-\mathrm{MCM})$ и зондом Nanosensor $(b, d, f, h-$ MCM предварительно созданной доменной структуры).

зондом Nanosensor, имеющим более высокое значение магнитного момента (рис. $4, b, d, f, h$ ). Вначале в два прохода проводилось сканирование области $2 \times 2 \mu \mathrm{m}^{2}$, и при этом пленка локально перемагничивалась. Затем в один проход сканировалась область $5 \times 5 \mu \mathrm{m}^{2}$. В результате в намагниченной предварительно области исходной структуры размером $2 \times 2 \mu \mathrm{m}^{2}$ были выявлены изолированные круглые домены, являюшиеся, предположительно, магнитными скирмионами. Как видно из представленных данных МСМ, таких изолированных доменов (скирмионов) образуется гораздо больше в случае облученной пленки CoPt, а именно, при флюенсе ионов $\mathrm{He}^{+}=3 \cdot 10^{14} \mathrm{~cm}^{-2}$. С увеличением флюенса до $5 \cdot 10^{14} \mathrm{~cm}^{-2}$ доменная структура предварительно намаг- 
Результаты исследований исходных и облученных пленок методом мандельштам-бриллюэновской спектроскопии

\begin{tabular}{c|c|c}
\hline $\begin{array}{c}\text { Флюенс } \\
\text { ионов, } \mathrm{cm}^{-2}\end{array}$ & $\begin{array}{c}\text { Сдвиг стоксовой } \\
\text { и антистоксовой } \\
\text { компонент спектра, MHz }\end{array}$ & $\begin{array}{c}\text { Константа } \\
\text { ВДМ, } \mathrm{mJ} / \mathrm{m}^{2}\end{array}$ \\
\hline 0 & 320 & 0.41 \\
$1 \cdot 10^{13}$ & 300 & 0.39 \\
$5 \cdot 10^{13}$ & 401 & 0.521 \\
$3 \cdot 10^{14}$ & 645 & 0.838 \\
$5 \cdot 10^{14}$ & 335 & 0.435 \\
$7 \cdot 10^{14}$ & 188 & 0.244 \\
$1 \cdot 10^{15}$ & 198 & 0.256
\end{tabular}

ниченной области $2 \times 2 \mu \mathrm{m}^{2}$ в процессе сканирования вначале начинает модифицироваться под действием зонда, затем быстро релаксирует и в итоге практически полностью совпадает с лабиринтной доменной структурой сканируемой области $5 \times 5 \mu \mathrm{m}^{2}$ (рис. $4, h$ ).

Исследования исходных и облученных образцов пленок CoPt методом мандельштам-бриллюэновской спектроскопии показали сдвиг стоксовой и антистоксовой компонент спектра на 320 и $645 \mathrm{MHz}$ для исходного и облученного образца (флюенс ионов $-3 \cdot 10^{14} \mathrm{~cm}^{-2}$ ) соответственно (таблица). Необходимо отметить, что при изменении полярности магнитного поля величина сдвига по абсолютному значению не изменялась. Полученные данные позволили оценить константы взаимодействия Дзялошинского-Мория, которые для исходного и облученного образца составили 0.41 и $0.838 \mathrm{~mJ} / \mathrm{m}^{2}$ соответственно. Наличие в пленках $\mathrm{CoPt}$ взаимодействия Дзялошинского-Мория со сравнительно высокими постоянными подтверждает возможность формирования магнитных скирмионов. Возрастание сдвига стоксовой и антистоксовой компонент спектра и увеличение константы взаимодействия Дзялошинского-Мория свидетельствуют об активации образования скирмионов в пленке $\mathrm{CoPt}$, облученной ионами $\mathrm{He}^{+}$с флюенсом $3 \cdot 10^{14} \mathrm{~cm}^{-2}$.

Перейдем к обсуждению результатов эксперимента. Обнаруженные в исходном образце магнитные домены (рис. $4, b$ ) интерпретируются как магнитные скирмионы, возникающие спонтанно при намагничивании сформированной пленки CoPt. Ионное облучение приводит к модификации магнитной структуры, что проявляется в изменении вида магнитополевых зависимостей намагниченности, повороте оси легкого намагничивания от перпендикулярного направления к положению в плоскости пленки и модуляции распределения изолированных доменов (скирмионов) в намагниченной пленке. Таким образом, ионное облучение является инструментом, позволяющим управлять формированием скирмионов.

Как отмечалось выше, магнитные вихри (скирмионы) или магнитные ,пузырьки“ формируются в структурах $\mathrm{Co} / \mathrm{Pt}$ (полученных методом магнетронного распыления), в частности, с использованием упорядоченных сеток: это либо локально облученные области в необлученной матрице, либо это диски со слоем кобальта на поверхности $[4,13]$. Диаметр модифицированных областей, повторяющихся с периодом 200-300 nm, составлял $100-150 \mathrm{~nm}$. В обоих случаях реализуется одна и та же ситуация: наноразмерные области с пониженной степенью ортогональной анизотропии встроены в матрицу с ортогональной анизотропией. Благодаря этим особенностям авторы $[4,13]$ демонстрируют в исследованиях методом магнитно-силовой микроскопии образование закрепленных магнитных вихрей (скирмионподобных состояний) или магнитных „пузырьков“ [4]. При этом для формирования решеток наноразмерных областей используется малодоступное и дорогостоящее оборудование (ионное травление в установке вторичной ионной масс-спектрометрии, локальная имплантация с размером пучка $5 \mathrm{~nm}$ и шагом сканирования $2 \mathrm{~nm}$ ).

В отличие от структур $\mathrm{Co} / \mathrm{Pt}$, полученных магнетронным распылением, в пленках $\mathrm{CoPt}$, изготовленных методом электронно-лучевого испарения, возможно формирование магнитных скирмионов без дополнительной технологической обработки. Исследования с помощью мандельштам-бриллюэновской спектроскопии показывают наличие в таких пленках взаимодействия Дзялошинского-Мория. Одной из возможных причин такого поведения может быть неоднофазность слоев $\mathrm{CoPt}$, сформированных методом электронно-лучевого испарения. Можно предположить, что, по-видимому, они содержат две фазы, отличающиеся магнитными свойствами и степенью ортогональной магнитной анизотропии. Возможно, благодаря этому, использование метода магнитно-силовой микроскопии позволяет уже в исходном образце создавать круглые изолированные домены (скирмионы). Очевидно, облучение ионами гелия по-разному воздействует на включения отличающихся степенью ортогональной намагниченности фаз. При определенной плотности ионов реализуется ситуация, когда различия в магнитных свойствах двух фаз наиболее значительные (они, вероятно, резко отличаются ориентацией оси легкого намагничивания). Этот результат и продемонстрирован на МСМ-изображениях рис. 4 возможность образования не просто круглых доменов, а скирмионов подтверждается исследованиями мандельштам-бриллюэновской спектроскопии.

Таким образом, при выполнении настоящего исследования продемонстрировано влияние ионного облучения на магнитные свойства сплава $\mathrm{CoPt}$, сформированного методом электронно-лучевого испарения. Показано, что с увеличением флюенса ионов $\mathrm{He}^{+}$(с энергией $20 \mathrm{keV}$ ) от $1 \cdot 10^{13}$ до $1 \cdot 10^{15} \mathrm{~cm}^{-2}$ коэрцитивное поле уменьшается, а при флюенсе $\geq 1 \cdot 10^{15} \mathrm{~cm}^{-2}$ увеличивается латеральная составляющая оси легкого намагничивания. При определенных флюенсах $\left(3 \cdot 10^{14} \mathrm{~cm}^{-2}\right)$ в слое $\mathrm{CoPt}$ создаются условия, способствующие преимущественному образованию изолированных круглых доменов магнитных скирмионов. 


\section{Финансирование работы}

Работа выполнена при поддержке проектной части госзадания (№ 8.1751.2017/ПЧ) Министерства науки и высшего образования РФ и РФФИ (гранты 18-29-27026, 18-37-00358_мол_а, 18-57-76001_ЭРА_а, 18-29-19137_мк), а также при финансовой поддержке правительства Российской Федерации (соглашение № 074-02-2018-286) лаборатории терагерцовой спинтроники МФТИ.

\section{Конфликт интересов}

Авторы заявляют, что у них нет конфликта интересов.

\section{Список литературы}

[1] C. Chappert, H. Bernas, J. Ferre, V. Kottler, J-P. Jamet, Y. Chen, E. Cambril, T. Devolder, F. Rousseaux, V. Mathet, H. Launois. Science 280, 1919 (1998).

[2] J. Ferre, T. Devolder, H. Bernas, J.P. Jamet, V. Repain, M. Bauer, N. Vernier, C. Chappert. J. Phys. D: Appl. Phys. 36, 3103 (2003).

[3] O.L. Ermolaeva, N.S. Gusev, E.V. Skorohodov, Yu.V. Petrov, M.V. Sapozhnikov, V.L. Mironov. Materials 10, 1034 (2017).

[4] M.V. Sapozhnikov, S.N. Vdovichev, O.L. Ermolaeva, N.S. Gusev, A.A. Fraerman, S.A. Gusev, Yu.V. Petrov. Appl. Phys. Lett. 109, 042406 (2016).

[5] А.В. Здоровейщев, М.В. Дорохин, О.В. Вихрова, П.Б. Демина, А.В. Кудрин, А.Г. Темирязев, М.П. Темирязева. ФТТ 58, 2186 (2016).

[6] А.В. Кудрин, М.В. Дорохин, А.В. Здоровейщев, П.Б. Демина, О.В. Вихрова, И.Л. Калентьева, М.В. Ведь. ФТТ 59, 2203 (2017).

[7] А.Г. Темирязев, М.П. Темирязева, А.В. Здоровейщев, О.В. Вихрова, М.В. Дорохин, П.Б. Демина, А.В. Кудрин. ФTT 60, 2158 (2018).

[8] K. Everschor-Sitte, J. Masell, R.M. Reeve, M. Kläui. J. Appl. Phys. 124, 240901 (2018).

[9] А.В. Здоровейщев. Тр. IX Всеросс. шк.-семинара студентов, аспирантов и молодых ученых по направлению „Диагностика наноматериалов и наноструктур“. РГРТУ,Рязань T. 1, 72 (2017).

[10] http://www.SRIM.org

[11] http://www.asu.edu/clas/csss/NUE/FIBSputterCalcYamamura.html

[12] A.V. Sadovnikov, E.N. Beginin, K.V. Bublikov, S.V. Grishin, S.E. Sheshukova, Yu.P. Sharaevskii, S.A. Nikitov. J. Appl. Phys. 118, 203906 (2015).

[13] М.В. Сапожников, О.В. Ермолаева, Е.В. Скороходов, Н.С. Гусев, М.Н. Дроздов. Письма в ЖЭТФ 107, 378 (2018).

Редактор Е.Ю. Флегонтова 